Supporting Information

\title{
Manganese oxide catalyzed hydrolysis of polyphosphates
}

\author{
Biao Wan, ${ }^{\dagger}$ Rixiang Huang,,${ }^{\dagger}$ Julia M. Diaz, ${ }^{\ddagger}$ Yuanzhi Tang $*, \dagger$ \\ ${ }^{\dagger}$ School of Earth and Atmospheric Sciences, Georgia Institute of Technology, Atlanta, GA \\ 30332-0340, USA \\ ${ }^{\ddagger}$ Department of Marine Sciences, Skidaway Institute of Oceanography, University of Georgia, \\ Savannah, GA 31411, USA
}

*Corresponding author. Email: yuanzhi.tang@ eas.gatech.edu; Phone: 404-894-3814

\author{
Submit to \\ ACS Earth and Space Chemistry
}

\author{
Total 17 pages \\ 3 texts \\ 12 figures \\ 2 tables
}




\section{Text S1. Characterizations of $P$ compounds and Mn oxides}

Solution ${ }^{31} \mathrm{P}$ nuclear magnetic resonance (NMR) spectroscopy was used to characterize the dissolved phosphate reagents (40 mM total $\mathrm{P}$ concentration) (Figure $\mathrm{S} 1$ ). $\mathrm{P}_{2}$ displayed a peak at $-6.28 \mathrm{ppm}$, while $\mathrm{P}_{3}, \mathrm{P}_{6}, \mathrm{P}_{10}$, and $\mathrm{P}_{45}$ showed signals between -6 and $-24 \mathrm{ppm}$. As shown in Figure $\mathrm{S} 1$, with increasing chain length, there was a decrease of the terminal $\mathrm{P}$ group signal (around -6 ppm) and an increase of the middle P group signal (around $-22 \mathrm{ppm}$ ). Previous studies proposed the determination of polyphosphate chain length based on the ratio of the peak area between the phosphate end-groups and middle-groups for solution ${ }^{31} \mathrm{P}$ NMR spectrum. ${ }^{1-3} \mathrm{P}_{2}$ only displayed the signal from end-group phosphate and $\mathrm{P}_{45}$ mainly showed the signal from middle-group phosphates, consistent with the absence of middle-group in $\mathrm{P}_{2}$ and the small ratio between end-group to middle group (2:43) for $\mathrm{P}_{45}$. Using this approach, analysis of the ${ }^{31} \mathrm{P}$ NMR spectra (Figure S1d) indicated that the average chain length of the polyphosphate sodium salt (Na-polyP) is $\sim 10$. We thus approximate the molecular formula of Na-polyP to be $\mathrm{Na}_{12} \mathrm{P}_{10} \mathrm{O}_{31}$ with 10 monomers $\left(-\mathrm{PO}_{3} \mathrm{Na}\right)$. Similar approach was used to estimate the average chain length of other polyphosphate reagents, which were determined to be between 3 and 45 .

Calcium polyphosphate (Ca-polyP) granules were synthesized by mixing $100 \mathrm{~mL}$ of 40 $\mathrm{mM} \mathrm{CaCl}_{2}$ solution and $100 \mathrm{~mL} \mathrm{P} 10$ solution with a total $\mathrm{P}$ concentration of $40 \mathrm{mM}$, according to previous procedures for synthesizing other Ca phosphate minerals. ${ }^{4}$ The synthesized solids were repeatedly washed by deionized (DI) water, centrifuged, and freeze-dried. Solid state ${ }^{31} \mathrm{P}$ NMR analysis of the synthesized solids showed two chemical shifts at -9.09 and 24.13 ppm (Figure S2), consistent with the reported values for Ca phosphate glass, ${ }^{5}$ and different from NMR spectra of common Ca phosphate minerals (e.g., brushite, hydroxylapatite) ${ }^{6}$

Four types of $\mathrm{Mn}$ oxides with different structure were used for this study, including $\alpha$ $\mathrm{MnO}_{2}, \beta-\mathrm{MnO}_{2}, \delta-\mathrm{MnO}_{2}$, and birnessite. $\beta-\mathrm{MnO}_{2}$ was purchased from Alfa Aesar. Other $\mathrm{Mn}$ oxides were synthesized according to previously reported methods for $\alpha-\mathrm{MnO}_{2},{ }^{7} \delta-\mathrm{MnO}_{2},{ }^{8}$ and birnessite. ${ }^{9}{ }^{10}$ All solids were repeatedly rinsed with DI water and freeze-dried. Mn oxide structure was characterized by X-ray diffraction (XRD) using a Panalytical Empyrean diffractometer $(\mathrm{Cu}$ $\mathrm{K} \alpha$ radiation) or a Bruker D8 Advanced X-ray diffractometer (Mo radiation). All oxides were confirmed to be phase pure (Figure S3). Specific surface area of Mn oxides was determined by Brunauer-Emmett-Teller (BET) gas adsorption analysis using an Autosorb-1-MP surface pore analyzer (Quantachrome Corp.). The surface areas of $\alpha-\mathrm{MnO}_{2}, \beta-\mathrm{MnO}_{2}, \delta-\mathrm{MnO}_{2}$, and birnessite were determined to be $146.43 \pm 0.32,2.03 \pm 0.07,125.72 \pm 0.6$, and $27.4 \pm 0.6 \mathrm{~m}^{2} \mathrm{~g}^{-1}$, respectively.

\section{Text S2. Synthesis of P XAS reference standard: $\alpha-\mathrm{MnO}_{2}$ adsorbed orthophosphate}

Before orthophosphate adsorption, a $2.0 \mathrm{~g} \mathrm{~L}^{-1} \alpha-\mathrm{MnO}_{2}$ suspension was dispersed in $0.1 \mathrm{M}$ $\mathrm{NaCl}$ and adjusted to a final $\mathrm{pH}$ of $6.0 \pm 0.05$ using $\mathrm{HCl}$ and $\mathrm{NaOH}$. Samples containing $10.0 \mathrm{~mL}$ of stock suspension were then added to $10.0 \mathrm{~mL}$ of a series of P-contained solutions (100, 200, $400,600,800,1000 \mu \mathrm{M})$ at $\mathrm{pH} 6.0$ in $0.1 \mathrm{M} \mathrm{KCl}$. The suspensions were equilibrated by shaking at $200 \mathrm{rpm}$ for $24 \mathrm{~h}$, during which the $\mathrm{pH}$ of each batch sample was manually adjusted to $\mathrm{pH} 6.0$ \pm 0.05 at $1,6,12$, and $24 \mathrm{~h}$, respectively. After $24 \mathrm{~h}$ of equilibration, the suspensions were 
centrifuged at 16,000 $\mathrm{g}$ for $10 \mathrm{~min}$, and the supernatants were filtered through a $0.22-\mu \mathrm{m}$ Millipore membrane to analyze orthophosphate concentration and adsorption density. The centrifuged wet pastes with highest adsorption density was freeze-dried for P XANES analysis as a reference standard (referred to as $\alpha-\mathrm{MnO}_{2}$ adsorbed orthophosphate).

\section{Text S3. Mn K-edge XAS analysis}

Mn K-edge XAS analysis was conducted for Mn oxides to investigate their average oxidation state. Mineral powders were finely ground and packed in Teflon sample holders covered with Kapton tape. XAS data was collected at Beamline 5-BM-D at the Advanced Photon Source (APS, Lemont, IL) using a vortex detector and $\mathrm{Si}(111)$ monochromators (with $40 \%$ detuning to avoid higher order harmonics). Energy calibration used Mn foil. Two scans were collected and averaged. Analysis of the Mn XANES spectra for each sample showed no photo-reduction under the X-ray beam. XAS data analysis was performed using Ifeffit. ${ }^{11}$ Linear combination fitting (LCF) of the Mn XANES region was conducted to determine the relative percentage of $\mathrm{Mn}$ (II), $\mathrm{Mn}$ (III), and $\mathrm{Mn}(\mathrm{IV})$ species and the average oxidation state (AOS) following the Combo method ${ }^{12}$ which was used in previous studies. ${ }^{13}$ Specifically, best quantitative results are obtained when the unknown spectrum is fit to a weighted sum of all 17 reference spectra in the database with the fractions of species constrained to be non-negative (Combo method). ${ }^{12}$ For the fitting of our samples, five $\mathrm{Mn}$ reference standards were finally chosen to represent the best quantitative result. They contained (1) REF4_2: Ramsdellite, $\mathrm{Mn}(\mathrm{IV}) \mathrm{O}_{2}$ for $\mathrm{Mn}(\mathrm{IV})$; (2) REF4_3: $\mathrm{Ca}_{2} \mathrm{Mn}_{3}^{I V} \mathrm{O}_{8}$ for $\mathrm{Mn}(\mathrm{IV})$; (3) REF4_4: potassium birnessite (KBi), $\mathrm{K}_{0.296}\left(\mathrm{Mn}_{0.926}^{I V} \square_{0.074}\right) \mathrm{O}_{2} \cdot 0.4 \mathrm{H}_{2} \mathrm{O}$ for $\mathrm{Mn}(\mathrm{IV})$; (4) $\mathrm{REF} 3 \_4: \mathrm{Mn}_{2}^{I I I} \mathrm{O}_{3}$ for $\mathrm{Mn}(\mathrm{III})$; and (5)REF2_8: $\mathrm{MnSO}_{4} \cdot \mathrm{xH}_{2} \mathrm{O}$ for $\mathrm{Mn}(\mathrm{II})$. 
Table S1. First-order kinetics fitting parameters for data shown in Figure 2.

\begin{tabular}{|c|c|c|c|c|c|}
\hline \multicolumn{3}{|c|}{ Experimental condition } & \multirow{2}{*}{ Reaction time (h) } & \multirow{2}{*}{$\mathbf{k}^{\mathbf{1}}$ ) } & \multirow{2}{*}{$\mathbf{R}^{\mathbf{2}}$} \\
\cline { 1 - 2 } PolyP chain length & Mineral & $\mathbf{C a}^{\mathbf{2 +}}$ concentration & & & \\
\hline $\mathrm{P}_{10}$ & $\alpha-\mathrm{MnO}_{2}$ & - & 120 & 0.155 & 0.828 \\
\hline $\mathrm{P}_{10}$ & $\alpha-\mathrm{MnO}_{2}$ & $500 \mu \mathrm{M}$ & 120 & 0.441 & 0.917 \\
\hline $\mathrm{P}_{10}$ & $\beta-\mathrm{MnO}_{2}$ & - & 120 & 0.001 & 0.932 \\
\hline $\mathrm{P}_{10}$ & $\beta-\mathrm{MnO}_{2}$ & $500 \mu \mathrm{M}$ & 120 & 0.002 & 0.983 \\
\hline $\mathrm{P}_{10}$ & $\delta-\mathrm{MnO}_{2}$ & - & 120 & 0.011 & 0.935 \\
\hline $\mathrm{P}_{10}$ & $\delta-\mathrm{MnO}_{2}$ & $500 \mu \mathrm{M}$ & 120 & 0.001 & 0.972 \\
\hline $\mathrm{P}_{10}$ & Birnessite & - & 120 & 0.969 \\
\hline $\mathrm{P}_{10}$ & Birnessite & $500 \mu \mathrm{M}$ & 48 & 0.043 & 0.970 \\
\hline $\mathrm{P}_{2}$ & $\alpha-\mathrm{MnO}_{2}$ & - & 48 & 0.943 \\
\hline $\mathrm{P}_{2}$ & $\alpha-\mathrm{MnO}_{2}$ & $500 \mu \mathrm{M}$ & 48 & 0.223 & 0.994 \\
\hline $\mathrm{P}_{3}$ & $\alpha-\mathrm{MnO}_{2}$ & - & 48 & 0.205 & 0.987 \\
\hline $\mathrm{P}_{3}$ & $\alpha-\mathrm{MnO}_{2}$ & $500 \mu \mathrm{M}$ & 48 & 0.263 & 0.940 \\
\hline $\mathrm{P}_{6}$ & $\alpha-\mathrm{MnO}_{2}$ & - & 48 & 0.488 & 0.983 \\
\hline $\mathrm{P}_{6}$ & $\alpha-\mathrm{MnO}_{2}$ & $500 \mu \mathrm{M}$ & 48 & 0.678 & 0.930 \\
\hline $\mathrm{P}_{45}$ & $\alpha-\mathrm{MnO}_{2}$ & - & 48 & 1.258 & 0.995 \\
\hline $\mathrm{P}_{45}$ & $\alpha-\mathrm{MnO}_{2}$ & $500 \mu \mathrm{M}$ & & &
\end{tabular}

Table S2. Linear combination fitting results of P K-edge XANES data on the solid products after Ca-polyphosphate granule reaction with $\alpha-\mathrm{MnO}_{2}$ at $\mathrm{pH} 6-9$ for $5 \mathrm{~d}$.

\begin{tabular}{|c|c|c|c|c|}
\hline \multirow{2}{*}{ Reaction pH } & \multicolumn{2}{|c|}{ Relative percentage of fitted reference compounds (\%) } & \multirow{2}{*}{ R-factor } \\
\cline { 2 - 5 } & Ca-polyP & $\begin{array}{c}\text { Amorphous Ca } \\
\text { phosphate }\end{array}$ & $\begin{array}{c}\text { o-MnO } \mathbf{2} \text { adsorbed } \\
\text { orthophosphate }\end{array}$ & \\
\hline 6.0 & $12.0 \pm 4.5$ & $59.4 \pm 5.2$ & $28.6 \pm 7.4$ & 0.0198 \\
\hline 7.5 & $12.0 \pm 4.6$ & $76.7 \pm 5.3$ & $11.3 \pm 7.6$ & 0.0279 \\
\hline 9.0 & - & $77.4 \pm 3.6$ & $22.6 \pm 5.6$ & 0.0103 \\
\hline
\end{tabular}



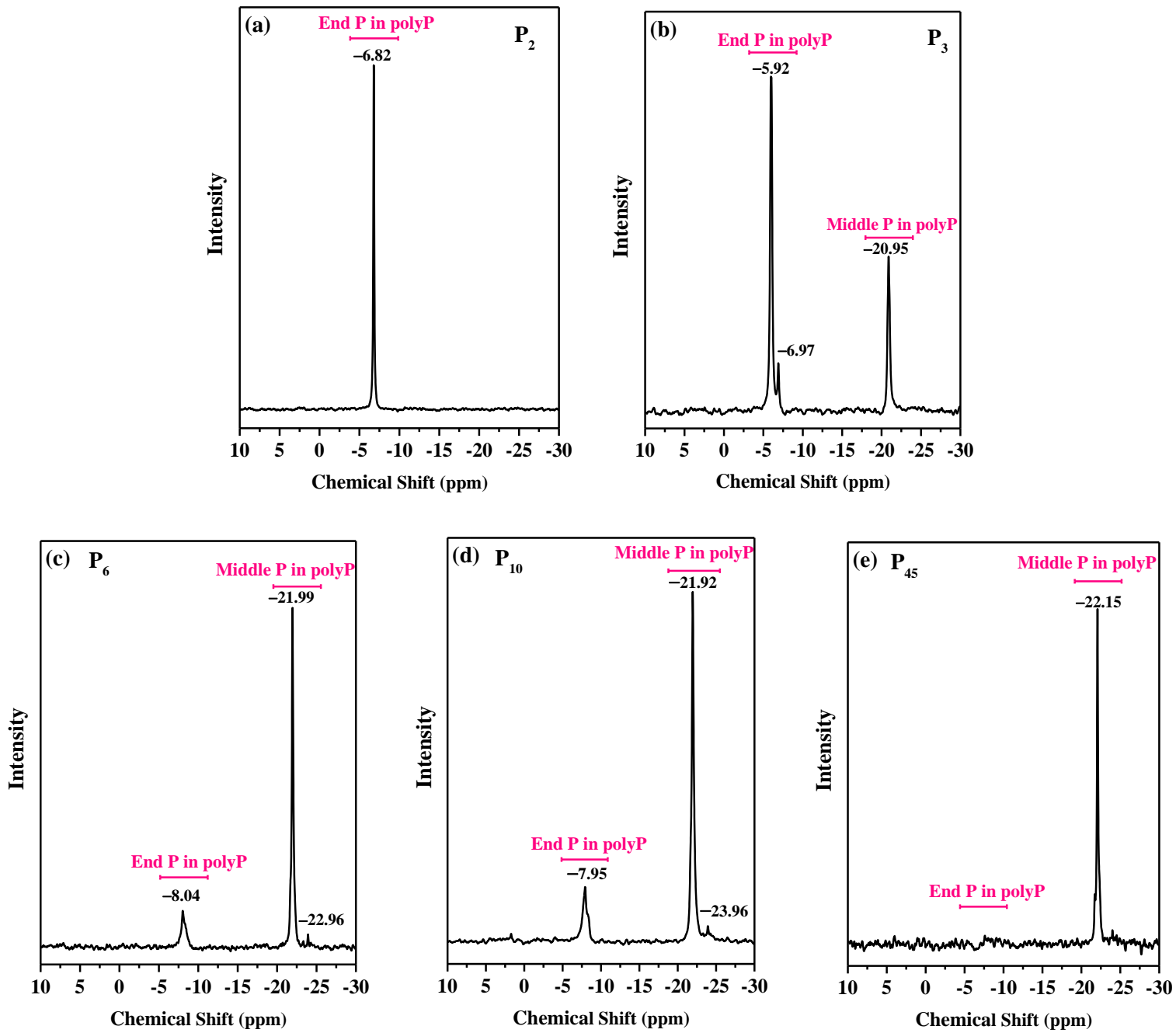

Figure S1. ${ }^{31} \mathrm{P}$ solution NMR spectra of polyphosphate stock solutions prepared from corresponding Na-salts at total $\mathrm{P}$ concentration of $40 \mathrm{mM}$ each: (a) $\mathrm{P}_{2}$, (b) $\mathrm{P}_{3}$, (c) $\mathrm{P}_{6}$, (d) $\mathrm{P}_{10}$, and (e) $\mathrm{P}_{45}$. 


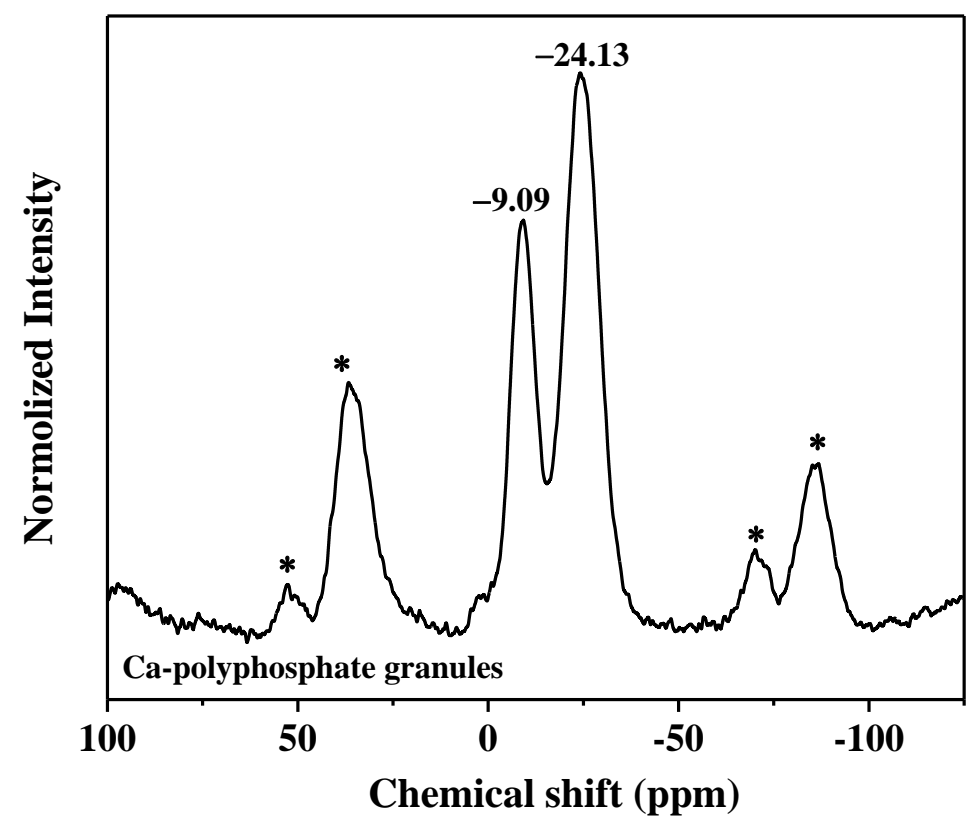

Figure S2. ${ }^{31} \mathrm{P}$ solid-state NMR spectra of the synthetic Ca-polyphosphate granules. Spin side bands are marked with asterisks. 

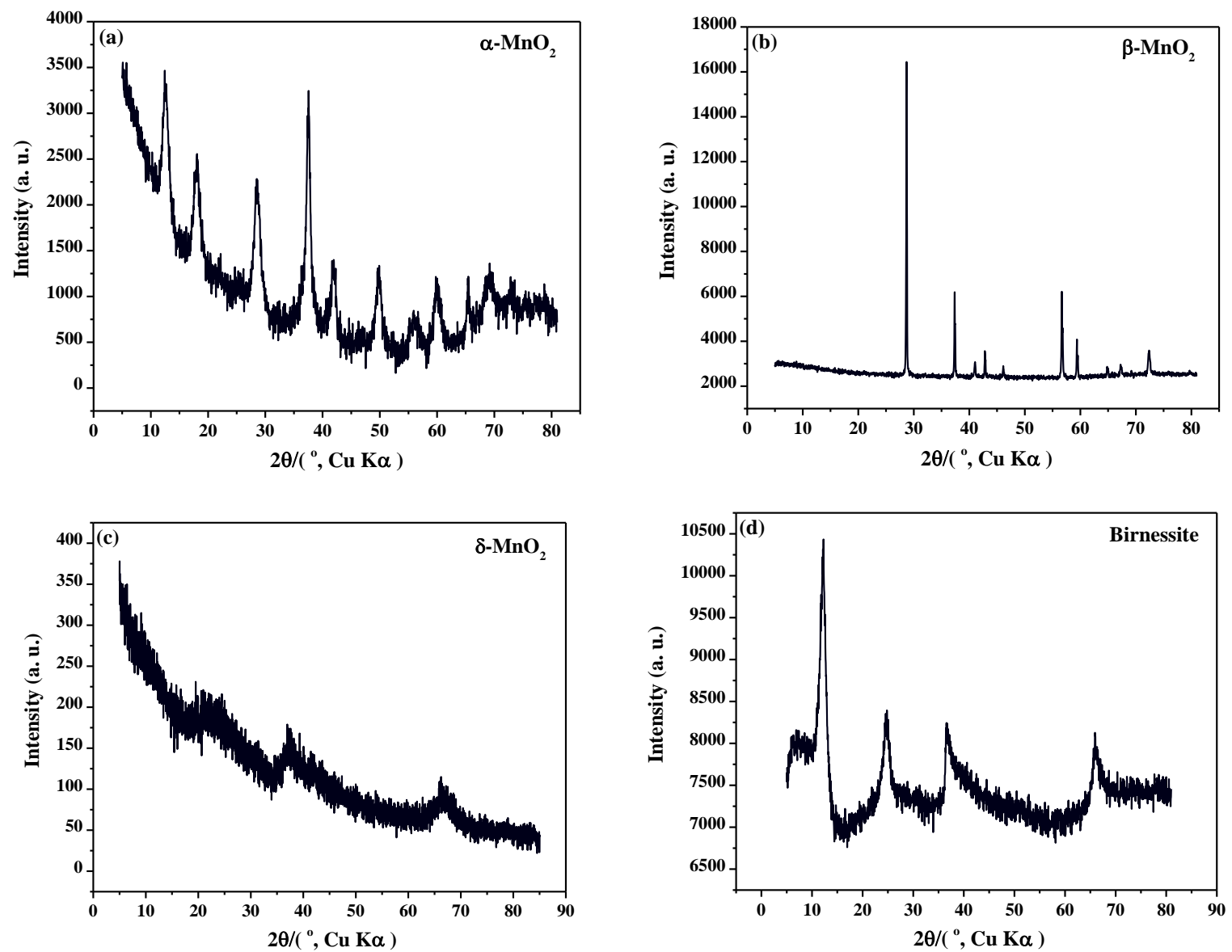

Figure S3. X-ray diffraction (XRD) data of $\alpha-\mathrm{MnO}_{2}$ (a), $\beta-\mathrm{MnO}_{2}$ (b), $\delta-\mathrm{MnO}_{2}$ (c), and birnessite (d). 

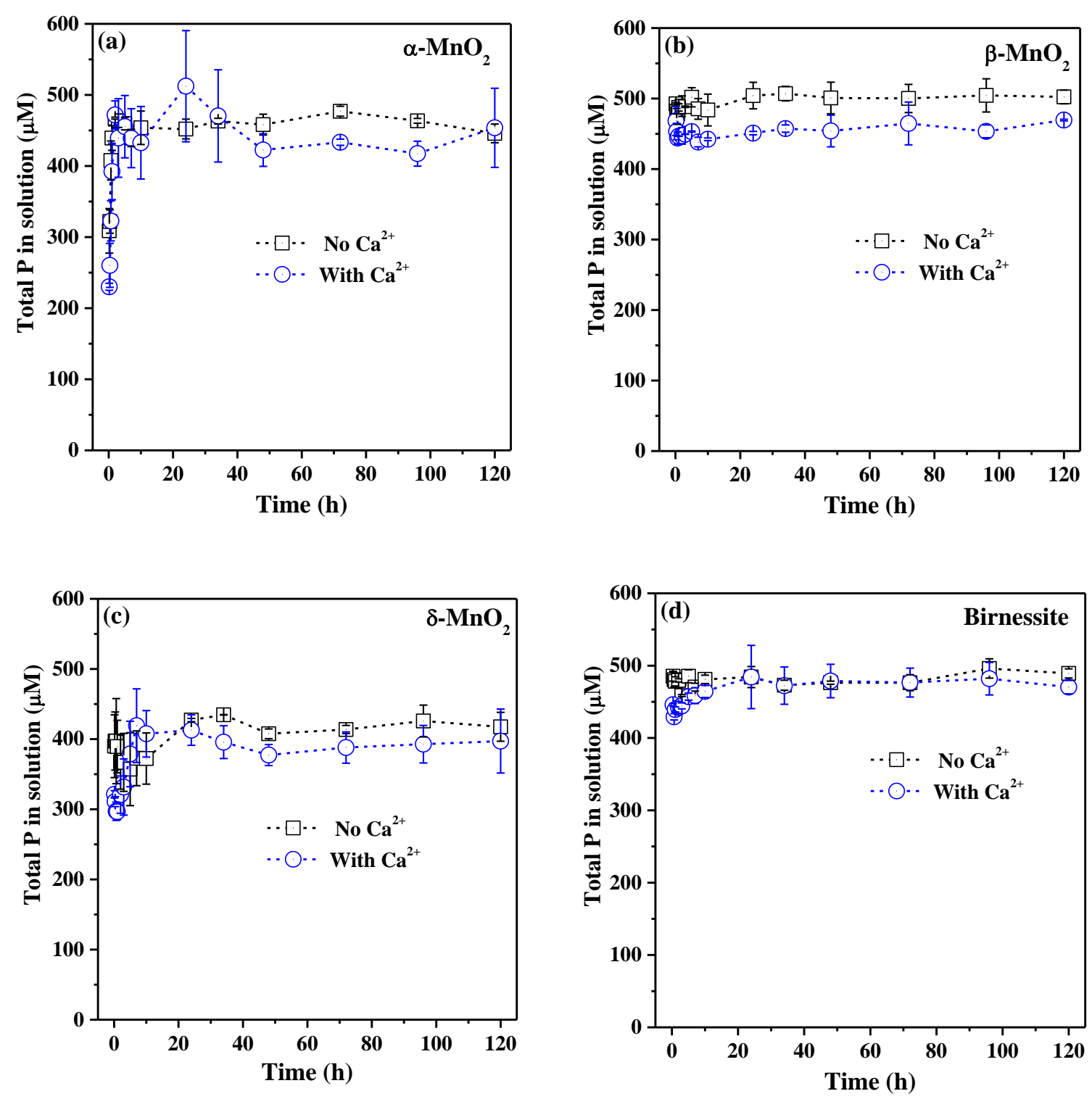

Figure S4. Change of total phosphorus concentration during mineral catalyzed hydrolysis of $\mathrm{P}_{10}$ by $\alpha-\mathrm{MnO}_{2}(\mathrm{a}), \beta-\mathrm{MnO}_{2}$ (b), $\delta-\mathrm{MnO}_{2}$ (c), and birnessite (d) at $\mathrm{pH} 6.0$ with or without $500 \mu \mathrm{M} \mathrm{Ca}^{2+}$. The total phosphate concentration for polyphosphate added was approximate $500 \mu \mathrm{M}$. 

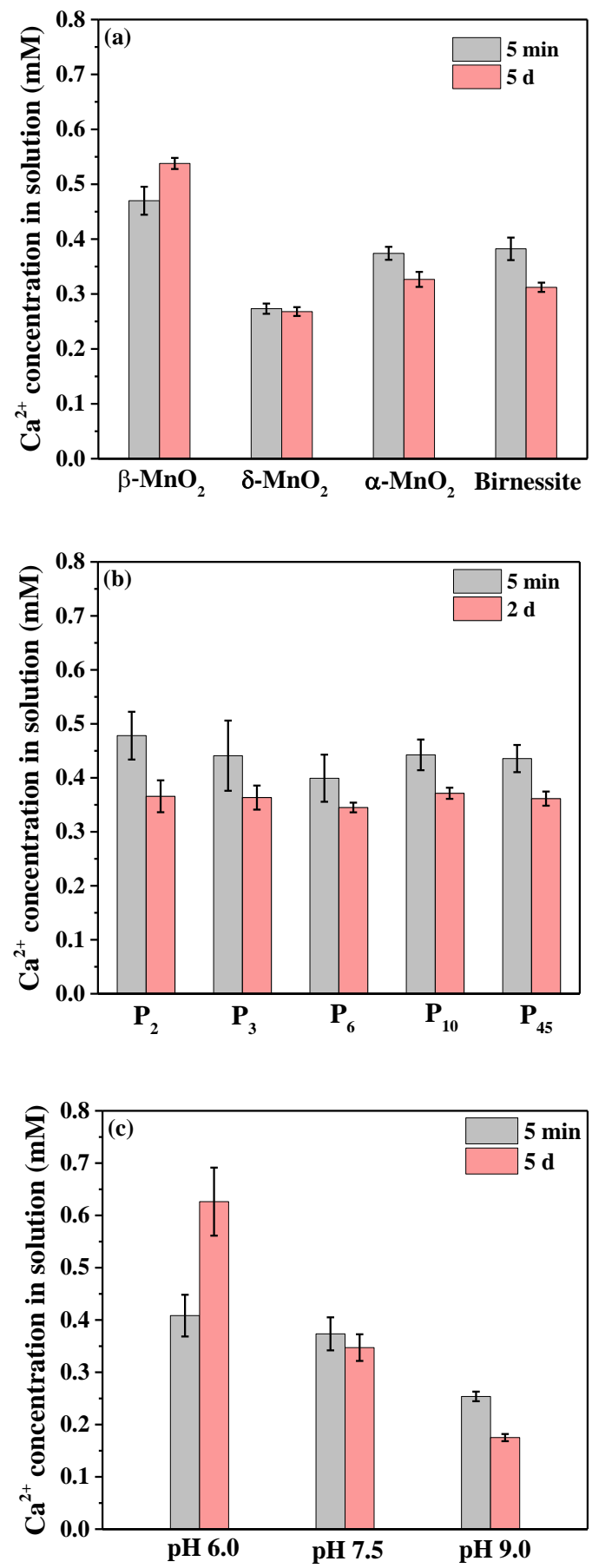

Figure S5. Concentration of $\mathrm{Ca}^{2+}$ in solution after polyphosphate reaction with $\mathrm{Mn}$ oxides for 5 $\min$ or $5 \mathrm{~d}$ at $\mathrm{pH}$ 6.0. All experiments used polyphosphate with total phosphate concentration of $500 \mu \mathrm{M}$ and Mn oxide loading of $0.4 \mathrm{~g} \mathrm{~L}^{-1}$. (a) $\mathrm{P}_{10}$ reaction with different Mn oxides; (b) $\alpha-\mathrm{MnO}_{2}$ reaction with polyphosphates with varied chain length ( $\mathrm{P}_{2}$ to $\mathrm{P}_{45}$ ); and (c) $\alpha-\mathrm{MnO}_{2}$ reaction with Ca-polyP granules. 

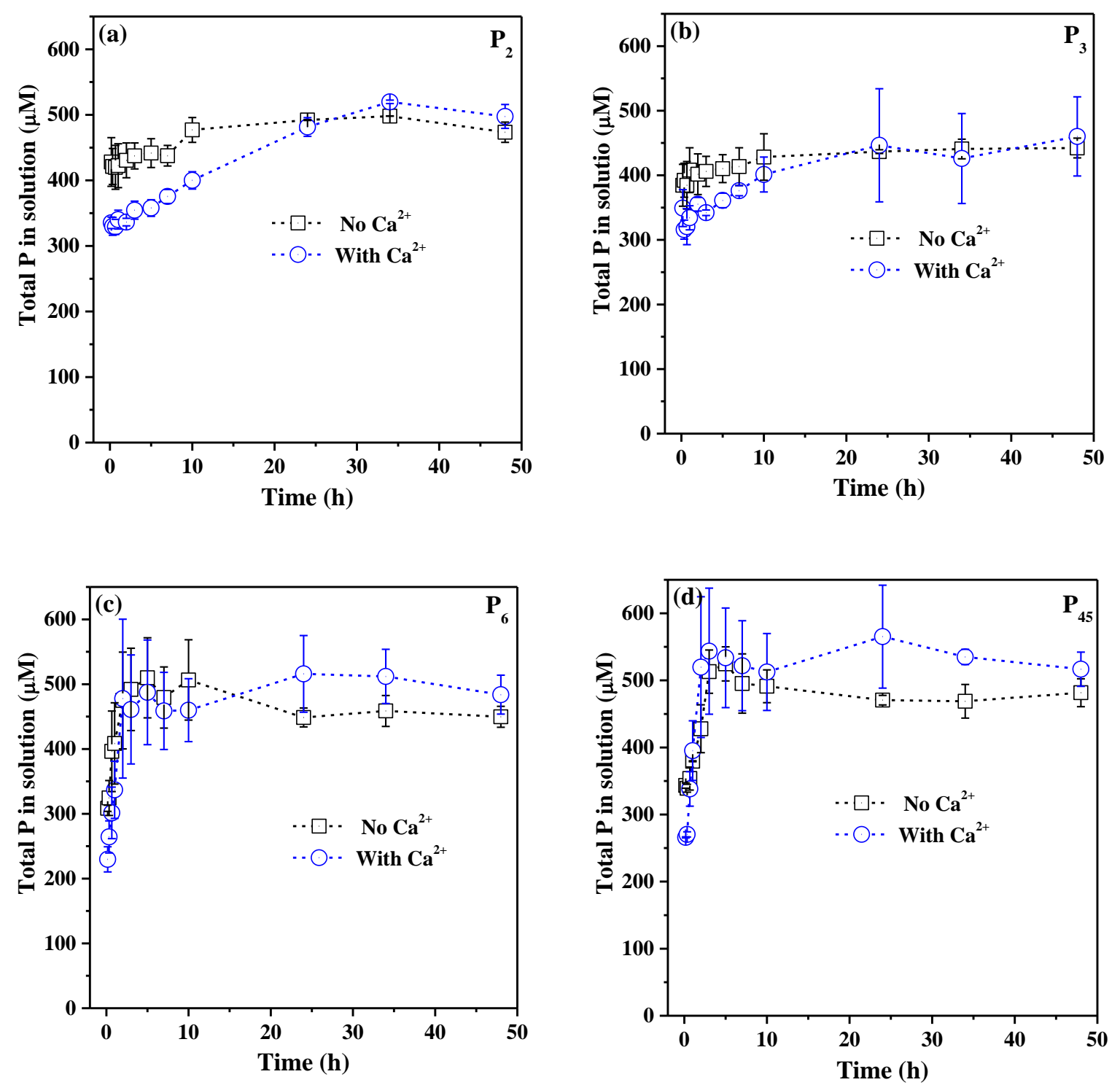

Figure S6. Total phosphorus concentration as a function of time during mineral catalyzed hydrolysis of various polyphosphates by $\alpha-\mathrm{MnO}_{2}$ at $\mathrm{pH} 6.0$ with or without $500 \mu \mathrm{M} \mathrm{Ca}^{2+}$ : (a) $\mathrm{P}_{2}$, (b) $\mathrm{P}_{3}$, (c) $\mathrm{P}_{6}$, and (d) $\mathrm{P}_{45}$. The total phosphate concentration for polyphosphate added was approximate $500 \mu \mathrm{M}$. 


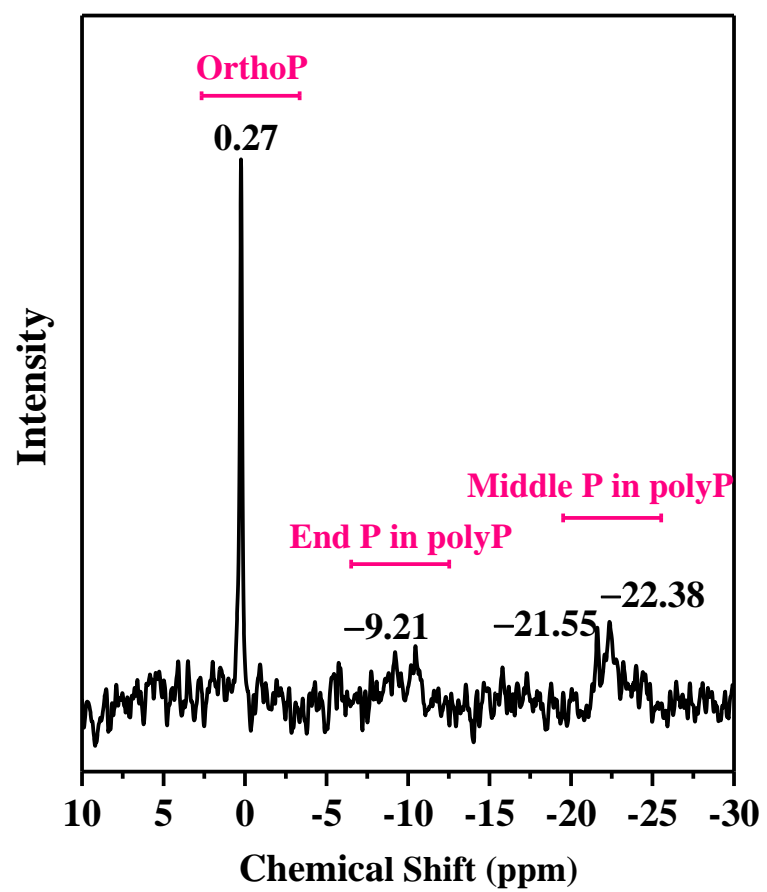

Figure S7. ${ }^{31} \mathrm{P}$ solution NMR spectra of the liquid supernatant after $\mathrm{P}_{10}$ reaction with $\alpha-\mathrm{MnO}_{2}$ (without $\mathrm{Ca}^{2+}$ ) at $\mathrm{pH} 6.0$ for 10 min (refer to Fig. 4). 


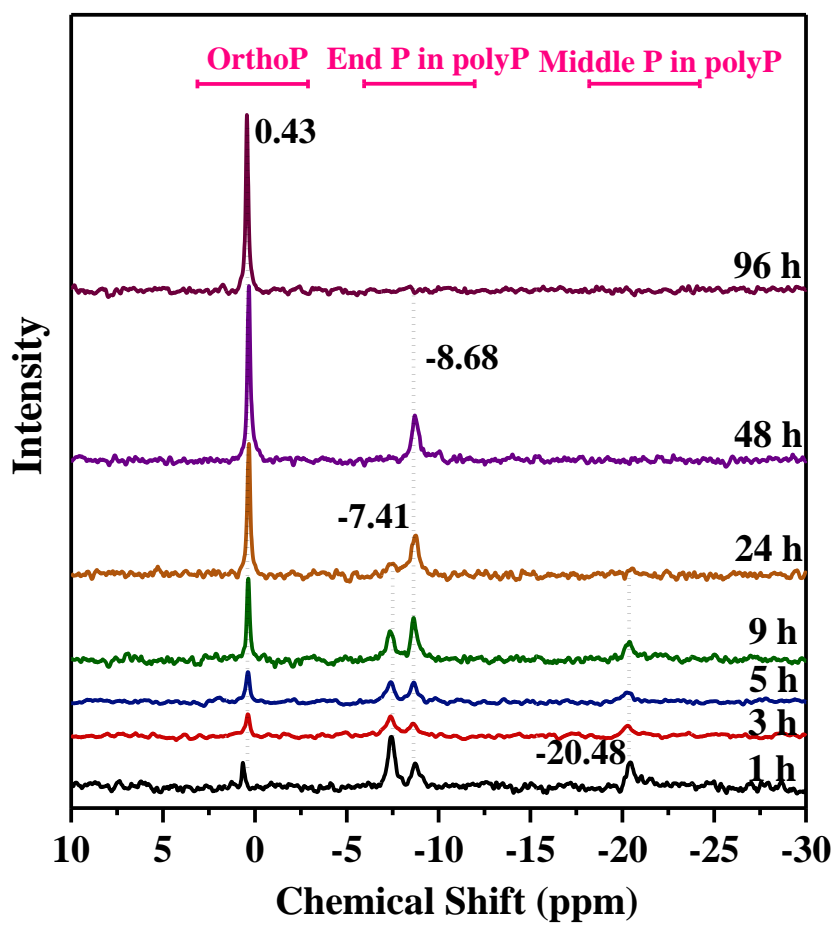

Figure S8. Time-resolved ${ }^{31} \mathrm{P}$ solution NMR spectra of the liquid supernatant after $\mathrm{P}_{3}$ reaction with $\alpha-\mathrm{MnO}_{2}$ at $\mathrm{pH}$ 6.0. The concentrations of $\alpha-\mathrm{MnO}_{2}, \mathrm{P}_{3}$, and $\mathrm{Ca}^{2+}$ were $0.04 \mathrm{~g} \mathrm{~L}^{-1}, 1 \mathrm{mM}$, and $3 \mathrm{mM}$, respectively. 

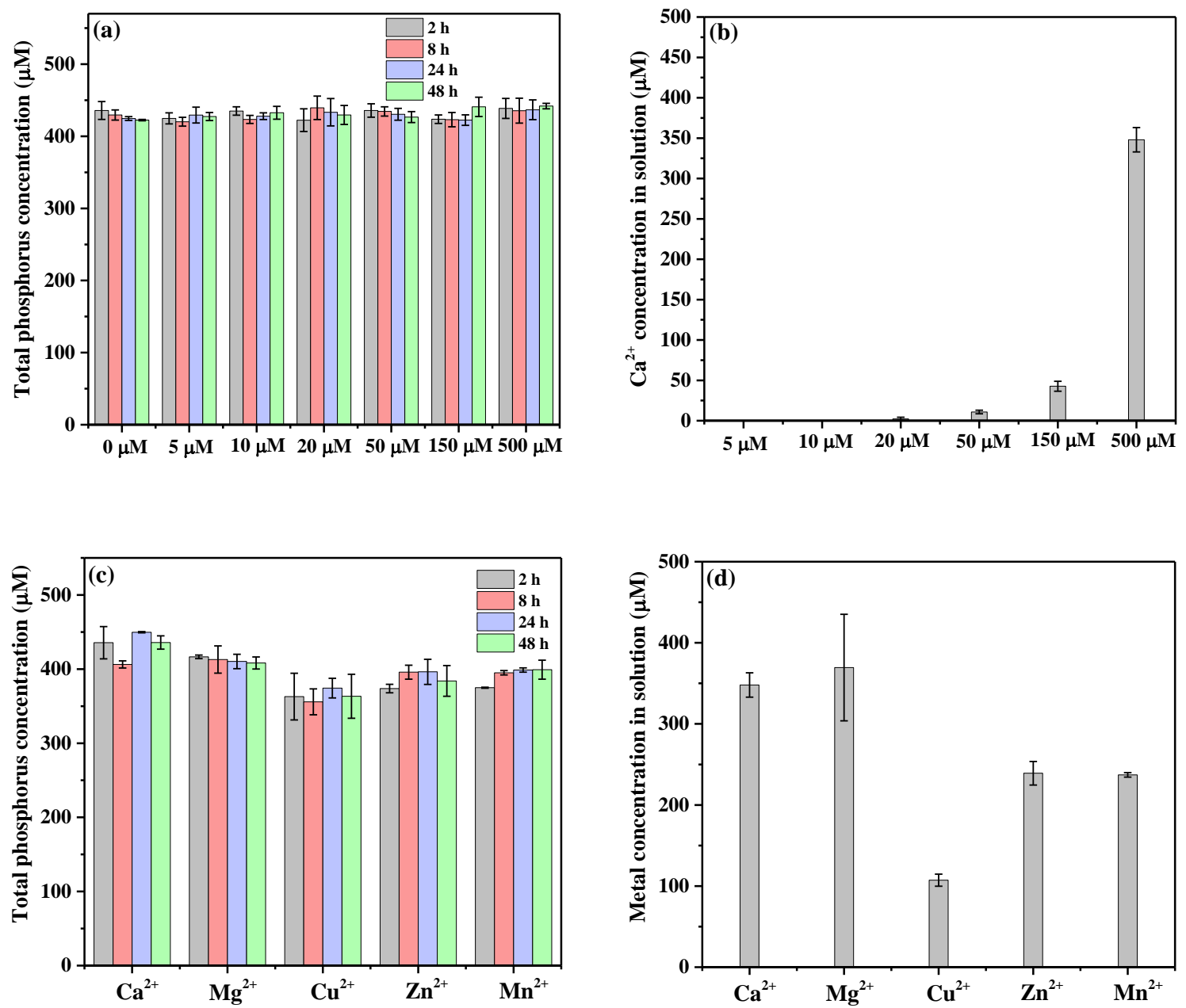

Figure S9. Effect of $\mathrm{Ca}^{2+}$ concentration and different metal cations on mineral catalyzed hydrolysis of polyphosphate $\mathrm{P}_{10}$ by $\delta-\mathrm{MnO}_{2}$ at $\mathrm{pH}$ 6.0. All experiments were conducted with $\mathrm{P}_{10}$ (total phosphate concentration $500 \mu \mathrm{M}$ ), $\delta-\mathrm{MnO}_{2}$ concentration of $0.1 \mathrm{~g} \mathrm{~L}^{-1}$, and background electrolyte of $0.1 \mathrm{M} \mathrm{NaCl}$. (a) Total $\mathrm{P}$ concentration in the supernatant after reaction in the presence of 0-500 $\mu \mathrm{M} \mathrm{Ca}^{2+}$ for 2-48 h, and (b) corresponding $\mathrm{Ca}^{2+}$ concentration in the supernatant at 48 h. (c) Total $\mathrm{P}$ concentration in the supernatant after reaction in presence of $500 \mu \mathrm{M}$ metal cations for 2-48 h, and (d) corresponding metal ion concentrations in the supernatant at $48 \mathrm{~h}$ (with a starting concentration of $500 \mu \mathrm{M}$ each). 


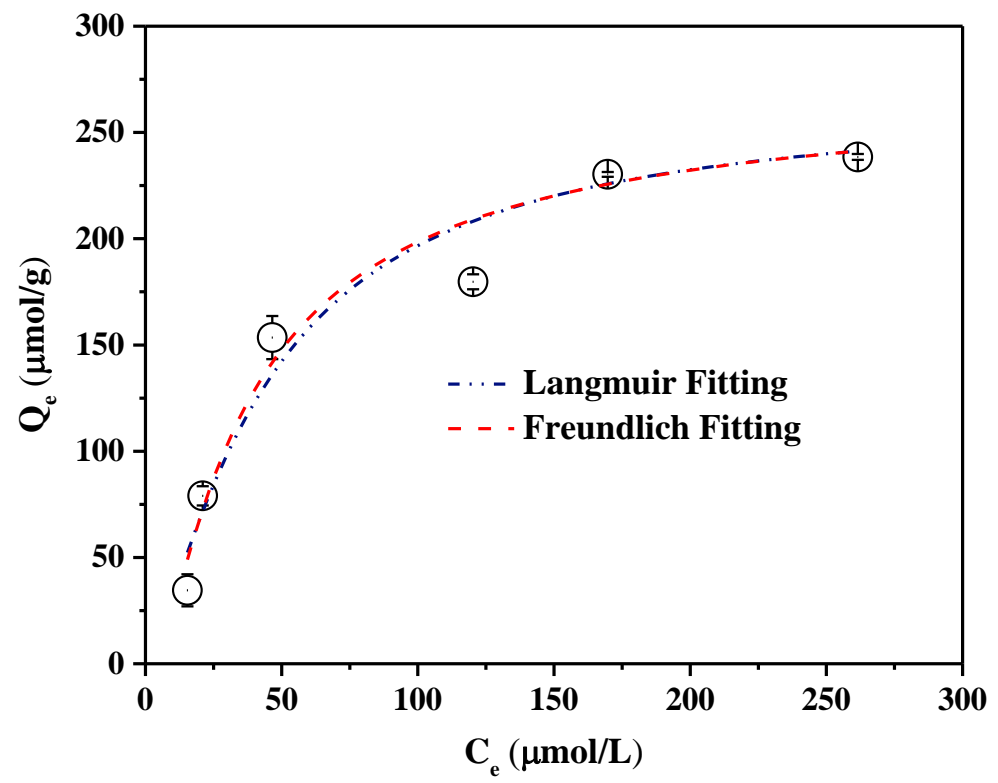

Figure S10. Phosphate adsorption isotherm on $\delta-\mathrm{MnO}_{2}$ (reaction condition: $\alpha-\mathrm{MnO}_{2}=1.0 \mathrm{~g} \mathrm{~L}^{-1}$, orthophosphate concentration $=50-500 \mu \mathrm{M}, \mathrm{NaCl}=0.1 \mathrm{M}, \mathrm{pH}=6.0$ ). Dashed lines are the fitting results using Langmuir or Freudnlich models. Error bars represent the results from duplicates. 

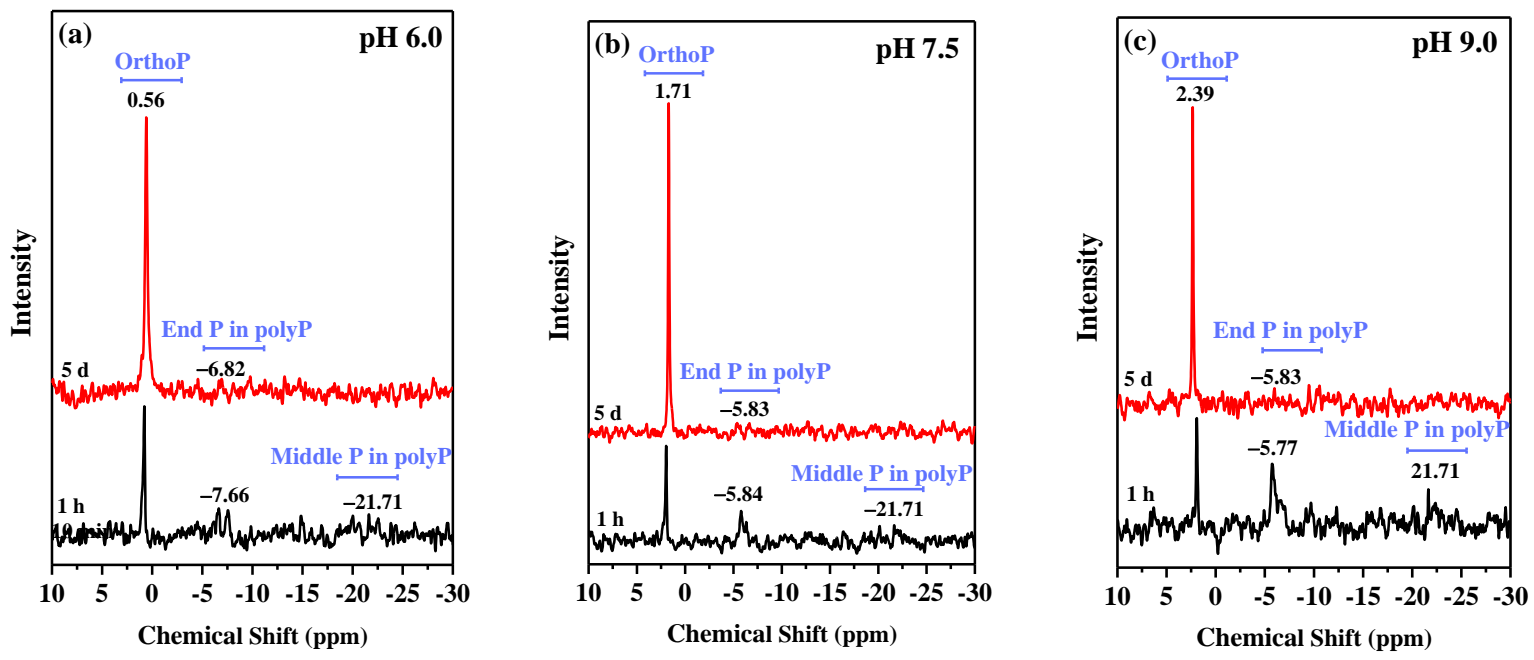

Figure S11. ${ }^{31} \mathrm{P}$ solution NMR spectra of the supernatant after Ca-polyP granule reaction with $\alpha$ $\mathrm{MnO}_{2}$ at $\mathrm{pH} 6.0$ (a), $\mathrm{pH} 7.5$ (b), and $\mathrm{pH} 9.0$ (c) for $1 \mathrm{~h}$ or $5 \mathrm{~d}$. 

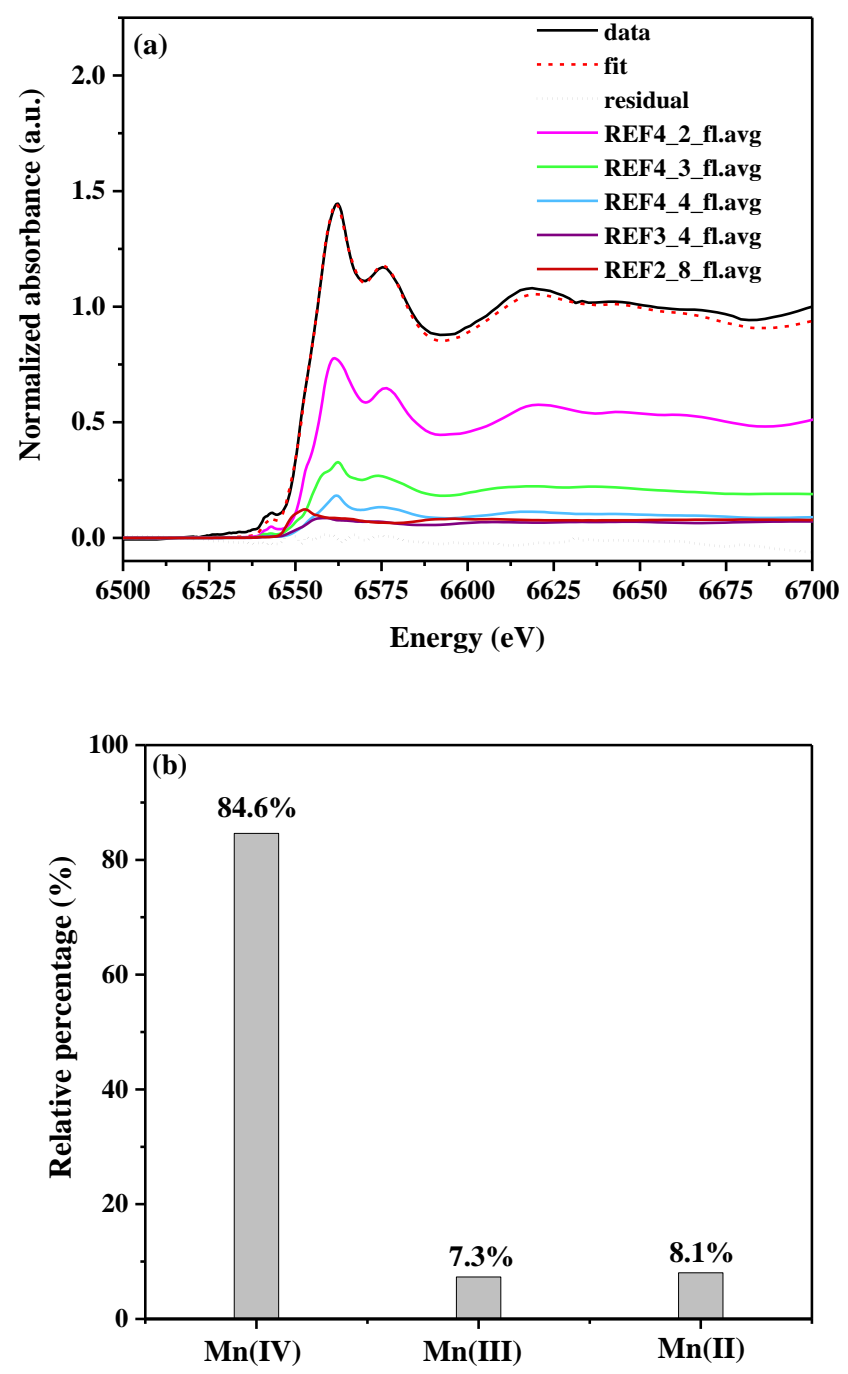

Figure S12. Mn XANES spectra (a) (black lines) and linear combination fitting (LCF) results (red dash lines) of $\alpha-\mathrm{MnO}_{2}$ phases using reference from the previous study. ${ }^{12}$ Reference compounds used for LCF are: REF4_2: Ramsdellite, Mn(IV)O2; REF4_3: $\mathrm{Ca}_{2} \mathrm{Mn}_{3}^{I V} \mathrm{O}_{8}$; REF4_4: potassium birnessite (KBi), $K_{0.296}\left(M_{0.926}^{I V} \square_{0.074}\right) O_{2} \cdot 0.4 H_{2} O$; REF3_4: $M n_{2}^{I I I} O_{3}$; REF2_8: $\mathrm{MnSO}_{4} \cdot \mathrm{xH}_{2} \mathrm{O}$. Relative percentage (b) of $\mathrm{Mn}(\mathrm{II})$, (III), and (IV) in $\alpha-\mathrm{MnO}_{2}$ phases, determined by LCF results in Figure S12a. 


\section{References}

1. Choi, S. H.; Collins, J. N. R.; Smith, S. A.; Davis-Harrison, R. L.; Rienstra, C. M.; Phosphoramidate end labeling of inorganic polyphosphates: Facile manipulation of polyphosphate for investigating and modulating its biological activities, Biochemistry 2010, 49, (45), 9935-9941. 2. Fang, W.; Sheng, G. P.; Wang, L. F.; Ye, X. D.; Yu, H. Q., Quantitative evaluation of noncovalent interactions between polyphosphate and dissolved humic acids in aqueous conditions. Environ. Poll. 2015, 207, 123-129.

3. Huang, R.; Wan, B.; Hultz, M.; Diaz, J. M.; Tang, Y., Phosphatase-mediated hydrolysis of linear polyphosphates, Environ. Sci. Technol. 2018, 52, (3), 1183-1190.

4. Wan, B.; Yan, Y.; Liu, F.; Tan, W.; Chen, X.; Feng, X., Surface adsorption and precipitation of inositol hexakisphosphate on calcite: A comparison with orthophosphate. Chem. Geol. 2016, 421, 103-111.

5. Jäger, C.; Hartmann, P.; Witter, R.; Braun, M., New 2D NMR experiments for determining the structure of phosphate glasses: A review. J. Non-Cryst. Solids 2000, 263-264, 61-72.

6. He, Z.; Honeycutt, C. W.; Xing, B.; McDowell, R. W.; Pellechia, P. J.; Zhang, T., Solidstare Fourier transformation infrared and ${ }^{31} \mathrm{P}$ nuclear magnetic resonance spectral features of phosphate compounds. Soil Sci. 2007, 172, (7), 501-515.

7. Inman, M. P.; Beattie, J. K.; Jones, D. R.; Baldwin, D. S., Abiotic hydrolysis of the detergent builder tripolyphosphate by hydrous manganese dioxide. Water Res. 2001, 35, (8), 19871993.

8. Ginder-Vogel, M.; Landrot, G.; Fischel, J. S.; Sparks, D. L., Quantification of rapid environmental redox processes with quick-scanning x-ray absorption spectroscopy (Q-XAS). Proc. Natl. Acad. Sci. 2009, 106, (38), 16124-16128.

9. McKenzie, R. M., The synthesis of birnessite, cryptomelane, and some other oxides and hydroxides of manganese. Mineral. Mag. 1971, 38, (296), 493-502.

10. Zhu, M.; Farrow, C. L.; Post, J. E.; Livi, K. J. T.; Billinge, S. J. L.; Ginder-Vogel, M.; Sparks, D. L., Structural study of biotic and abiotic poorly-crystalline manganese oxides using atomic pair distribution function analysis. Geochim. Cosmochim. Ac 2012, 81, 39-55.

11. Ravel, B.; Newville, M., ATHENA, ARTEMIS, HEPHAESTUS: data analysis for X-ray absorption spectroscopy using IFEFFIT. J. Synchrotron Radiat. 2005, 12, (4), 537-541.

12. Manceau, A.; Marcus, M. A.; Grangeon, S., Determination of Mn valence states in mixedvalent manganates by XANES spectroscopy. Am. Mineral. 2012, 97, (5-6), 816-827.

13. Wang, Q.; Yang, P.; Zhu, M., Structural transformation of birnessite by fulvic acid under anoxic conditions. Environ. Sci. Technol. 2018, 52, (4), 1844-1853. 